\title{
Long Survival and Preservation of Good Visual Acuity in a Patient with Bilateral Diffuse Uveal Melanocytic Proliferation
}

\author{
Baudine C. van Noort ${ }^{a} \quad$ Jan E.E. Keunen ${ }^{b}$ Reinier O. Schlingemann ${ }^{c}$ \\ Marina Marinkovic ${ }^{a}$ \\ aDepartment of Ophthalmology, Leiden University Medical Centre, Leiden, The Netherlands; ${ }^{b}$ Department of \\ Ophthalmology, Radboud University Medical Centre, Nijmegen, The Netherlands; ' ${ }^{2}$ epartment of Ophthalmology, \\ Amsterdam Medical Centre, Amsterdam, The Netherlands
}

\section{Established Facts}

- Bilateral diffuse uveal melanocytic proliferation (BDUMP) is a rare, paraneoplastic syndrome with a high mortality rate and short mean survival time after diagnosis.

\section{Novel Insights}

- Prolonged survival and preservation of useful visual acuity is possible in BDUMP in rare cases.

\section{Keywords}

Bilateral diffuse uveal melanocytic proliferation - Uveal tumor · Paraneoplastic syndrome · Iris

\begin{abstract}
Purpose: To report a patient with bilateral diffuse uveal melanocytic proliferation (BDUMP) due to a lung carcinoma, who survived 9.5 years with preservation of good visual acuity after cataract surgery and curative chemotherapy with neoadjuvant radiation therapy. Methods: Clinical review of a patient with BDUMP. Results: We report the case of a
\end{abstract}

\section{KARGER}

E-Mail karger@karger.com www.karger.com/oop (c) 2018 The Author(s) Published by S. Karger AG, Basel

Karge Open access

This article is licensed under the Creative Commons AttributionNonCommercial-NoDerivatives 4.0 International License (CC BYNC-ND) (http://www.karger.com/Services/OpenAccessLicense) Usage and distribution for commercial purposes as well as any distribution of modified material requires written permission. 64-year-old man presenting with bilateral visual deterioration. Ophthalmological examination showed bilateral cataract, a small elevated non-pigmented tumor in the iris and multiple elevated, diffuse round pigmented choroidal lesions. Based on the clinical presentation, the diagnosis of BDUMP was suspected. After referral to an internal medicine specialist, a poorly differentiated non-small cell lung carcinoma was diagnosed and treated with chemotherapy followed by irradiation. After 3 years, spontaneous depigmentation of the choroidal lesions occurred. According to the literature, the mean survival of patients with BDUMP is 11.6 months. Our patient, however, survived for 9.5 years with 
preservation of good visual acuity after cataract extraction. Conclusion: This case illustrates that prolonged survival and preservation of useful visual acuity is possible in BDUMP. Cataract surgery should be considered in selected patients, and depigmentation of the lesions may occur during longterm follow-up.

(c) 2018 The Author(s)

Published by S. Karger AG, Basel

\section{Introduction}

Bilateral diffuse uveal melanocytic proliferation (BDUMP) is a rare, paraneoplastic syndrome. Diffuse bilateral proliferation of melanocytes in the uvea was first described by Machemer in 1966 [1]. In 1982, the condition was recognized by Barr et al. [2] as a syndrome and finally characterized by 5 cardinal signs by Gass et al. [3]: (1) multiple, round or oval, subtle red patches at the level of the retinal pigment epithelium; (2) a striking pattern of multifocal areas of early hyperfluorescence corresponding with these patches; (3) development of multiple, slightly elevated, pigmented and non-pigmented uveal melanocytic tumors, as well as thickening of the uveal tract; (4) exudative retinal detachment, and (5) rapid progression of cataract. To complete the syndrome, BDUMP

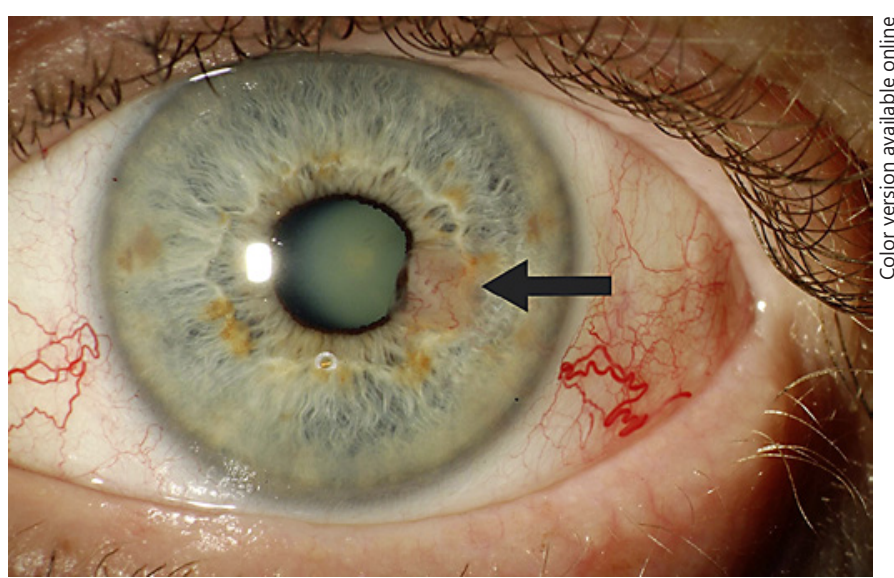

Fig. 1. Slit lamp photography of the iris lesion (arrow) and cataract in the left eye.
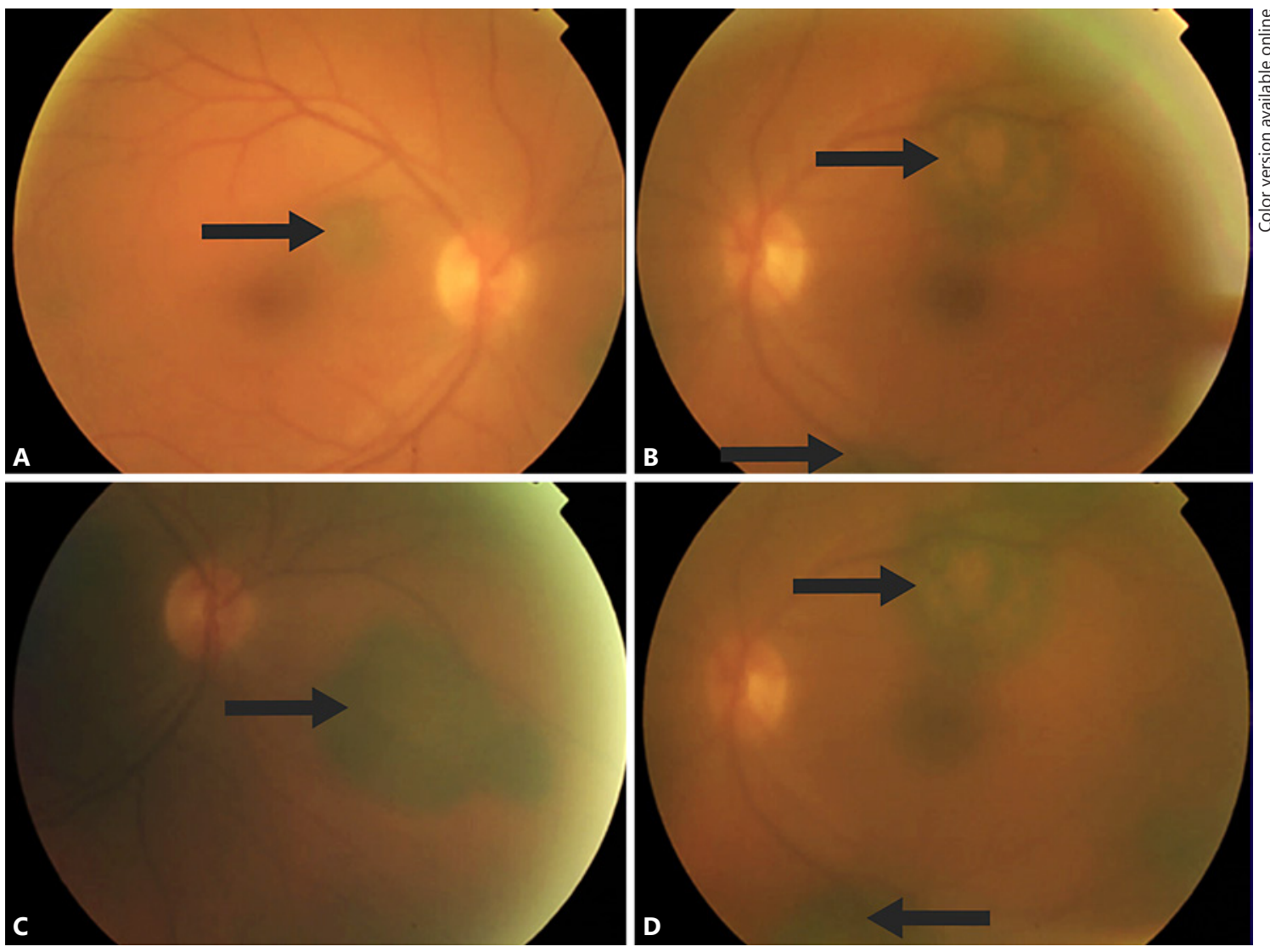

Fig. 2. Fundoscopic image of the pigmented lesions (arrows) before cataract extraction in the right eye (A, C) and left eye (B, D). 
has been associated with underlying visceral tumors such as lung, ovary, pancreas, gallbladder, colon, uterus and cervix carcinomas [3-5].

The pathogenesis of the melanocytic infiltration in BDUMP remains uncertain [4]. The mean age at onset is 64 years, and the mean time at onset of ocular symptoms to death described in previous literature is about 1 year [6]. The longest survival has been reported by Duong et al. [6]; their patient survived for 10.5 years after bilateral enucleation.

\section{Case Report}

A 64-year-old male patient visited the ophthalmic outpatient department of the Academic Medical Center (Amsterdam, The Netherlands) in 2004 with a bilateral drop in visual acuity. There was no past ocular history of note. Ophthalmological examination showed a best corrected visual acuity (BCVA) of 0.8 (Snellen) in the right eye (RE) and 0.3 (Snellen) in the left eye (LE). The anterior segment showed subcapsular cataract in both eyes $(\mathrm{RE}<\mathrm{LE})$ and a small elevated non-pigmented tumor on the left iris (Fig. 1). Fundoscopic examination was hampered by cataract in the LE, but showed several bilateral, slightly elevated, diffuse round pigmented choroidal lesions (Fig. 2). There was no exudative retinal detachment. Based on these ophthalmic clinical features, BDUMP was suspected, although choroidal metastases of skin melanoma were considered as well. The patient was referred to the internal medicine specialist and dermatologist for further investigation, and a poorly differentiated non-small cell lung carcinoma stage $3 \mathrm{~B}$ in the right lung without evidence for metastasis was diagnosed.

The patient received curative chemotherapy with neoadjuvant radiation therapy from 2004 to 2005 and total remission was achieved. Subsequently, bilateral regular phacoemulsification was performed, and the BCVA rose to 1.0 (Snellen) in both eyes. Dur- ing follow-up, visual acuity remained unchanged. After 3 years of follow-up, depigmentation of the choroidal lesions occurred (Fig. 3). A few years later, the patient underwent YAG-laser capsulotomy in both eyes. In 2012, 8 years after the diagnosis, a nonsmall cell lung carcinoma of the left lung, suspected for a new primary tumor due to the long disease-free interval, was found, and chemoradiation therapy was given. The initial response was successful. The patient died 9.5 years after the diagnosis BDUMP, still with good visual acuity.

\section{Discussion}

We describe a patient with BDUMP without distinct exudative retinal detachment and an atypical course with both prolonged preservation of excellent visual acuity after cataract surgery and almost 10 years' survival. To the best of our knowledge, no similar patient with good and stable visual acuity after BDUMP diagnosis has ever been described during a nearly 10 -year follow-up period. We speculate that the absence of an exudative retinal detachment might have been indicative of a milder underlying immune reaction. Furthermore, depigmentation of the choroidal lesions after prolonged follow-up has not been described in the literature, probably because most patients had limited survival after the diagnosis of BDUMP.

This case illustrates that prolonged survival and preservation of useful visual acuity is possible in patients with BDUMP. Cataract surgery should therefore be considered in selected patients, as they might benefit from the procedure. Depigmentation of the lesions can occur late in follow-up.
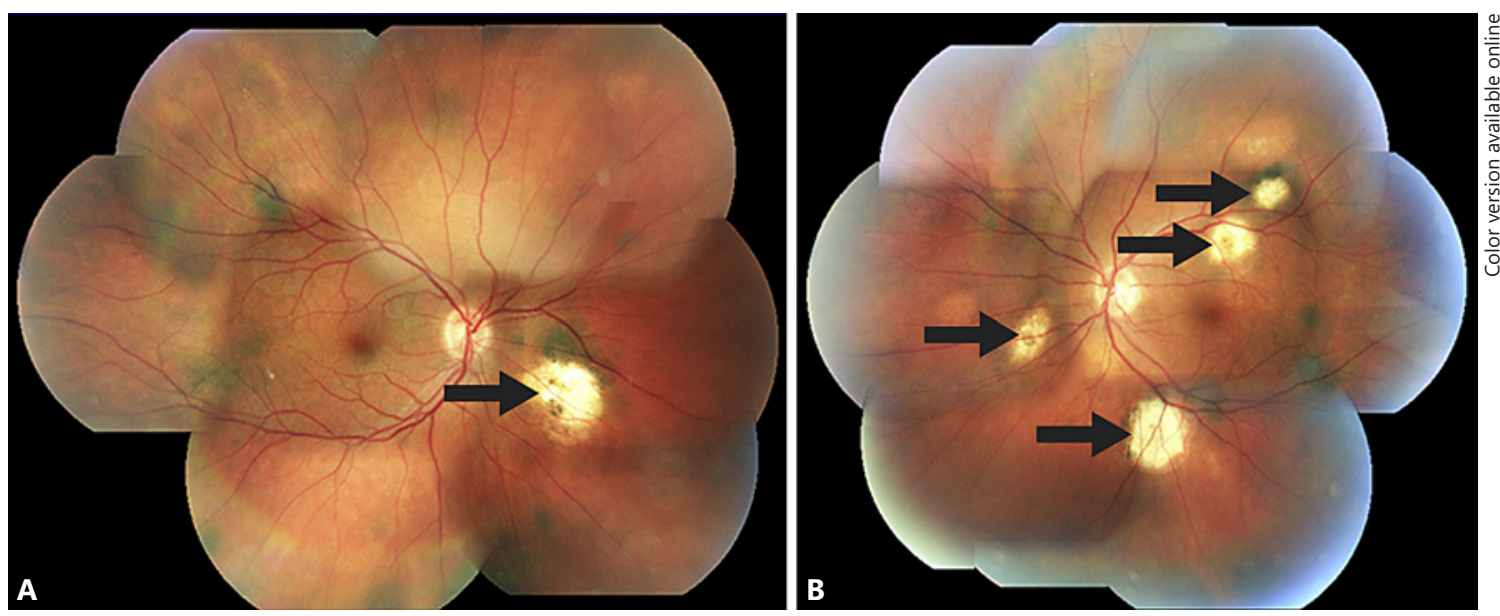

Fig. 3. Fundoscopic image of the depigmented lesions (arrows) after cataract extraction in the right eye (A) and left eye (B). 


\section{Statement of Ethics}

This case report was performed under approval of the Medical Ethics Review Committee of the Academic Medical Center. The Medical Research Involving Human Subjects Act (WMO) does not apply to this case report.

\section{Disclosure Statement}

The authors state they have no conflict of interest to disclose.

\section{References}

1 Machemer R: On the pathogenesis of the flat malignant melanoma (in German). Klin Monbl Augenheilkd 1966;148:641-652.

2 Barr CC, Zimmerman LE, Curtin VT, Font RL: Bilateral diffuse melanocytic uveal tumors associated with systemic malignant neoplasms. A recently recognized syndrome. Arch Ophthalmol 1982;100:249-255.

3 Gass JD, Gieser RG, Wilkinson CP, Beahm DE, Pautler SE: Bilateral diffuse uveal melanocytic proliferation in patients with occult carcinoma. Arch Ophthalmol 1990;108:527533.
4 Mittal R, Cherepanoff S, Thornton S, Kalirai H, Damato B, Coupland SE: Bilateral diffuse uveal melanocytic proliferation: molecular genetic analysis of a case and review of the literature. Ocul Oncol Pathol 2015;2:94-99.

5 O’Neal KD, Butnor KJ, Perkinson KR, Proia $\mathrm{AD}$ : Bilateral diffuse uveal melanocytic proliferation associated with pancreatic carcinoma: a case report and literature review of this paraneoplastic syndrome. Surv Ophthalmol 2003; 48:613-625.

6 Duong HV, McLean IW, Beahm DE: Bilateral diffuse melanocytic proliferation associated with ovarian carcinoma and metastatic malignant amelanotic melanoma. Am J Ophthalmol 2006;142:693-695. 